\title{
MARIMBONDOS (HYMENOPTERA: VESPIDAE) NA CULTURA POPULAR BRASILEIRA
}

WASPS (HYMENOPTERA: VESPIDAE) IN THE BRAZILIAN FOLKLORE

Syara Cesario Bravo de Noronha ${ }^{1 *}$, Paola Aparecida de Moura ${ }^{1}$, Taiguara Pereira de Gouvêa', Gabriel Teofilo-Guedes ${ }^{2}$, Marcos Magalhães de Souza ${ }^{1}$

\begin{abstract}
Resumo:
Marimbondos são insetos sociais de grande interesse e relevância para a espécie humana. Sua história natural se mistura à nossa por meio da construção do conhecimento empírico de culturas tradicionais, mas também do imaginário popular, fomentando o mito na criação das identidades dos grupos sociais. O Brasil apresenta um rico repertório cultural referindo-se à relação entre o povo brasileiro e os marimbondos, geralmente associado à suposta hostilidade de suas estratégias de defesa. Na ausência, contudo, de um compêndio que relacione tais obras, realizou-se o presente trabalho, visando a demonstrar o quão presentes estão os marimbondos na cultura do povo brasileiro. Para tanto, consultou-se a literatura especializada e obras da música e literatura popular. Os registros demonstram a presença dos marimbondos no cotidiano das comunidades do campo, em geral associados à transmissão de histórias e crendices, aos conhecimentos e práticas de medicina popular, ou à literatura regionalista. Assim, tem-se confirmado a estreita relação entre o povo brasileiro e a biodiversidade adjacente, o que aponta a necessidade de mais pesquisas para a reconstituição da história dessas relações, portanto, é reiterado que conhecer é o primeiro passo para preservar.
\end{abstract}

Palavras-chave: vespas sociais, insetos sociais, etnobiologia, etnoentomologia, etnografia.

\footnotetext{
1 Laboratório de Zoologia, Instituto Federal de Educação, Ciência e Tecnologia do Sul de Minas Gerais, Inconfidentes, MG, Brasil. ^syaradenoronha@gmail.com

${ }^{2}$ Departamento de Geologia e Recursos Naturais, Instituto de Geociências, Universidade Estadual de Campinas, Campinas, SP, Brasil.
} 


\section{Abstract:}

Wasps are social insects of great interest and importance for the human species. Their natural history is mixed with ours by building the empirical knowledge of traditional cultures, but also of folklore, promoting the myth in the creation of social groups' identity. Brazil owns a rich cultural framework referring to the relation between the brazilian people and wasps, in general related to the supposed hostility of their defense strategies. In the absence, yet, of a compendium that may relate such productions, we made this work, aiming to show how present the wasps are in the brazilian people's culture. For that purpose, we consulted the specialized literature and artworks from folk music and literature. The records demonstrate the presence of wasps within the field communities, in general associated to the transmission of histories and popular beliefs, to the popular medicine knowledge and practices, or to the regionalist literature. This way, we reaffirm the next relation between the brazilian people and the surrounding biodiversity, which suggests the need for a bigger research effort in reconstituting the history of such relations. So, we emphasize that knowing is the first step to preserving.

Keywords: social wasps, social insects, ethnobiology, ethnoentomology, ethnography.

\section{Introdução}

O termo marimbondo deriva do quimbundo, dialeto africano do noroeste de Angola que significa vespa (MENDONÇA, 2012); também foi o apelido atribuído pelos portugueses aos brasileiros, em função da revolta dos pernambucanos de 1852, que se insurgiram contra o registro obrigatório de nascimentos e óbitos (MELO, 1920; TERRA DA GENTE, 2009); e é um dos nomes populares mais utilizados no Brasil para designar as vespas sociais, insetos da ordem Hymenoptera, família Vespidae (SOUZA e ZANUNCIO, 2012).

As vespas sociais também são chamadas de 'caba' (SANTOS e FERREIRA, 2000; ARAUJO, 2008), termo oriundo do tronco linguístico tupi, falado em várias localidades do Brasil (POVOS INDÍGENAS NO BRASIL, s/d).

Vespidae engloba trés subfamílias sociais, Vespinae, Polistinae e Stenogastrinae, sendo que no Brasil há apenas a ocorrência de Polistinae, com três tribos: Polistini, Mischocyttarini e Epiponini (CARPENTER e MARQUES, 2001), perfazendo 381 espécies (SOMAVILLA et al., 2012)

Esses insetos sociais exibem dois comportamentos de fundação de colonia: por enxameamento, caracterizada pela participacão de milhares de indivíduos na construc,ão de novos ninhos; e fundação independente, em que a formac,ão dos ninhos é iniciada por uma única fêmea ou associac,ões entre duas ou mais (STARR, 1991; CARPENTER E MARQUES, 2001).

Os gêneros de Polistinae presentes no Brasil podem ser reconhecidos e/ou diferenciados basicamente pela arquitetura de seus ninhos, popularmente conhecidos como "caixas de marimbondos". A complexidade, a variação de formas e o tipo de fixação dessas estruturas, resultam em características particulares aos ninhos, como tamanho, presença ou ausência de invólucro, de pedúnculo, posição do orifício de entrada, entre outras. Os diferentes substratos utilizados para a fixação dos ninhos, que podem ser folhas, galhos, cipós, rochas ou construções humanas, possuem influência direta na diversidade de nidificações (SOMAVILLA et al., 2012). 
Os marimbondos são temidos comumente por suas ferroadas, que representam uma estratégia de defesa de suas colônias (BRITO et al., 2018). Tal comportamento resulta em relações interespecíficas que podem ser benéficas ou maléficas a outras espécies; todavia, devido à desinformação, ainda é comum no Brasil a prática de destruir as colônias (COSTA-NETO, 2003; SILVA et al., 2020). Esse equívoco acarreta prejuízos socioambientais, pois esses insetos sociais desempenham diferentes serviços ecológicos, com destaque para o controle biológico em diversas culturas agrícolas, como café, milho, cítricos, etc. (CARPENTER e MARQUES, 2001; JACQUES et al., 2019; PREZOTO et al., 2019).

Diante do exposto, observa-se que os marimbondos conseguem ocupar ambientes antrópicos, como cidades (ALVARENGA et al., 2010; OLIVEIRA et al., 2017) e áreas agrícolas (AUAD et al., 2010; DALLÓ et al., 2017), apresentando ampla distribuição no Brasil (SOUZA et al., 2020 a, b), portanto sua relação com humanos é próxima e explica diversas interações culturais (SOUZA e ZANUNCIO, 2012; SANTOS et al., 2015), tais como ritos (POSEY, 1979; SCHIMIDT e IKPENG, 2006; BOLLETTIN, 2013), usos medicinais (COSTANETO, 1999; 2000; 2005; COSTA-NETO e PACHECO, 2005; MOURA e MARQUES, 2008; ALVES, 2009; 2010), gastronômicos (COSTA-NETO e RAMOS-ELORDUY, 2006; APODONEPA e BARRETO, 2015) e outros.

Desssa maneira, realizou-se o presente trabalho com o relatar de histórias, lendas, crendices, brincadeiras, rituais, alimentac,ão, medicina popular e outras manifestac,̃os culturais sobre os marimbondos no Brasil, a fim de demonstrar o quão presentes estão esses insetos na cultura do povo brasileiro.

\section{Material e Métodos}

O estudo foi realizado entre janeiro e maio de 2021 e consistiu na revisão de literatura sobre mitos, lendas e etnozoologia de vespas sociais no Brasil. Para o estudo, foram analisados artigos publicados, dissertações, teses, capítulos de livros, resumos em congressos, músicas e vídeos relacionados à temática. Os trabalhos consultados no presente estudo foram obtidos das plataformas de pesquisa Scielo, Scopus, Google Scholar, Researchgate e Periódicos Capes a partir do uso das palavras-chave: ethnoentomology AND hymenoptera; ethnoentomology; ethnozoology AND brazil; comunidade AND marimbondos; comunidade AND vespas; insetos AND uso medicinal; vespas AND uso medicinal; hymenoptera AND uso medicinal; insetos AND comunidades AND tradicionais. Já as músicas e os vídeos foram obtidos a partir de busca no Google. O período de recorte de dados pesquisados foi de 1920 a 2020.

Para fins de organizacão do presente manuscrito, considerou-se a presença dos marimbondos nas categorias: (3.1) Nomes populares e comportamento de defesa; (3.2) Lendas, crendices, rituais e brincadeiras; (3.3) Alimentac,ão; (3.4) Medicina popular e, finalmente (3.5) Literatura e música popular. 


\section{Resultados e Discussão}

Foram encontradas em torno de 90 obras científicas (artigos, dissertações, teses, resumos e livros), sendo utilizadas 74 (excluindo grupos de vespas de hábito solitário e abelhas), além de seis músicas, uma revista magazine e três vídeos disponíveis no Youtube, o que produziu informações a partir de diferentes manifestações culturais, como se segue:

\subsection{Nomes populares e comportamento de defesa}

A relação de proximidade entre os marimbondos e as comunidades tradicionais pode ser observada pelos nomes populares atribuídos às diferentes espécies desses insetos presentes no cotidiano das pessoas (PADUA et al., 2017; SILVA et al., 2020). Em geral são empregados termos de profundo significado para aquelas comunidades, de modo que se evidencia um pouco do papel por elas atribuído aos marimbondos (Figura 1).
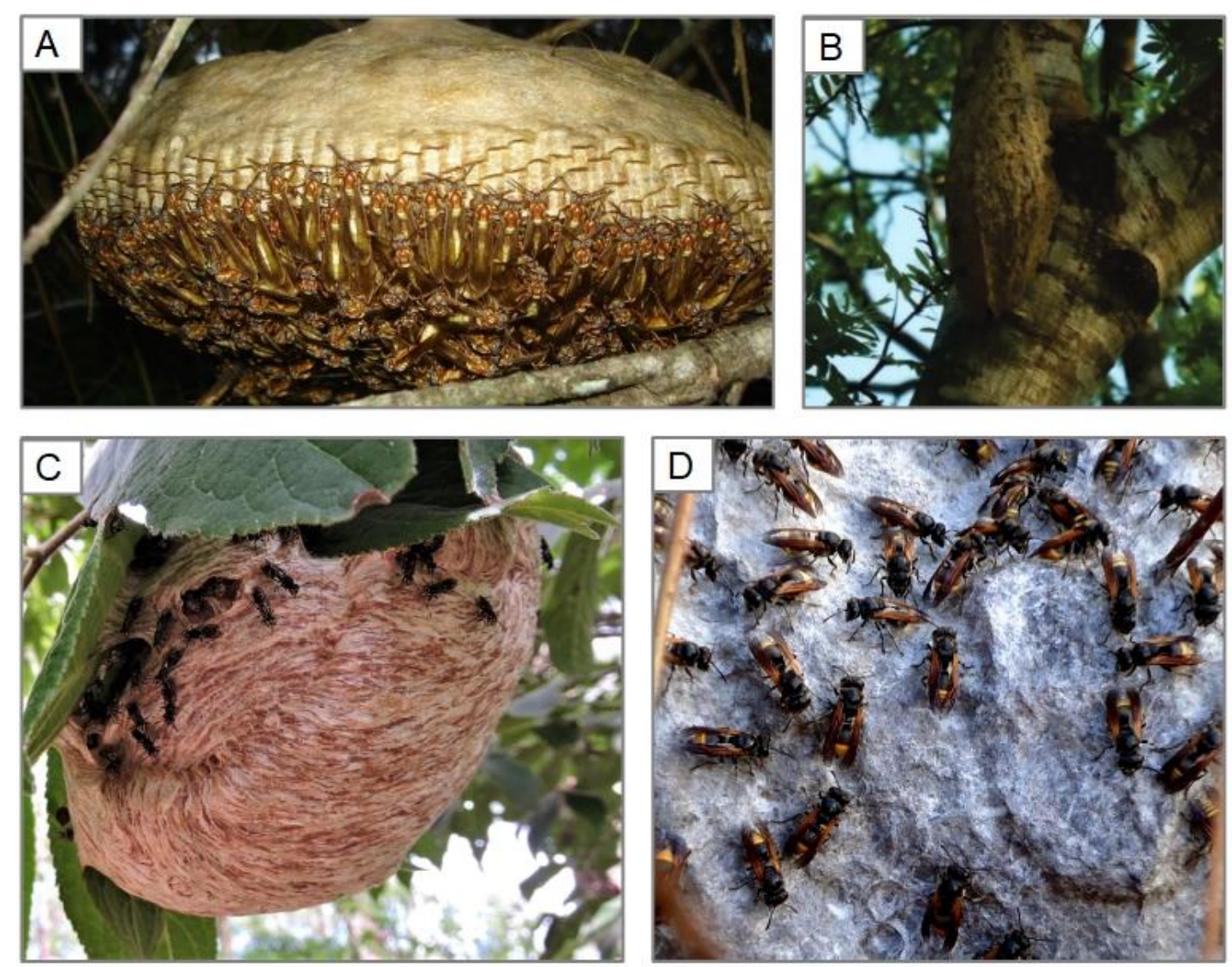

Figura 1. Espécies de marimbondos popularmente conhecidas; A. marimbondo-chapéu (Apoica pallens); B. marimbondoboca-garrafa (Chartergellus communis), C. marimbondo mirim (Protopolybia sedula); e D. Exu-do-pasto (Brachyastra lecheguana) (Fonte: Marcos Magalhães de Souza).

Os nomes populares atribuídos aos marimbondos geralmente estão relacionados a diferentes aspectos de sua biologia, tais como formato do ninho (marimbondo-peito-demoça; marimbondo-tatu, marimbondo-chapéu, marimbondo-boca-de-garrafa, marimbondo-pomba-de-cavalo, marimbondo-de-espeto ou marimbondo-de-fio); pelo comportamento de agressividade (marimbondo-transformador, marimbondo-flecheiro ou flecha, chumbinho, capetinha, exu-do-pasto, marimbondo-zumbidor); pelo local de nidificação (marimbondo-da-mata); pelos hábitos alimentares (marimbondo-carniceiro); pela cor ou tamanho (marimbondo-mirim, caboclo, cavalo, amarelo, branco e rajado), 
além daqueles já mencionados acima (SANTOS, 1985; COSTA-NETO, 1998; 2004; SOUZA et al., 2008; SOUZA e ZANUNCIO, 2012; APODONEPA e BARRETO, 2015; PADUA et al., 2017). Essa diversidade de etnoespécies citadas reflete uma relação próxima das pessoas com esses insetos, como discutido (PÁDUA et al., 2017), o que, entretanto, não assegura, na maioria das vezes, uma relação harmoniosa das comunidades para com esses insetos (BOMFIM et al., 2016).

Na verdade, os nomes populares atribuídos às espécies de marimbondos, frequentemente evidenciam a natureza de uma relação marcada por temor e apreensão, como mostrado pelas obras antes analisadas. Todavia, é sabido que boa parte dessa compreensão não diz respeito aos reais parâmetros etológicos desses animais, em termos de agressividade, docilidade e outras estratégias de defesa da colônia (RICHARDS, 1978; STRASSMANN et al., 1990; STARR, 1991; MATEUS et al., 1997; WENZEL, 1998; GIANNOTTI, 1999; SILVEIRA et al., 2015; SOUZA et al., 2020c), mas sim, à superlatividade do imaginário popular.

À luz dos princípios da seleção natural, espera-se que vespas sociais, assim como quaisquer outros organismos, não apresentem interesse em estabelecer relações de hostilidade e dominação, se não aquelas estritamente necessárias para o benefício das próprias espécies. Assim, a real hostilidade demonstrada pelos marimbondos não se deve a relações entre bem e mal, construções puramente relativas à cultura humana, mas sim a fatores ecológicos, tais como a disponibilidade de recursos e defesa da colônia e da prole, o que geralmente é mediado por sinalização hormonal (CHAVARRIA-PIZARRO e WEST-EBERHARD, 2010).

\subsection{Lendas, crendices, rituais e brincadeiras}

O livro "Aiho Ubuni Wasu'ú: o lobo guará e outras histórias do povo xavante" (PAPPIANI e LACERDA, 2014) mostra comunidades indígenas do estado do Mato Grosso, sob uma perspectiva mítica e poética, revelando, por meio da "História do Warazu", as proezas de um homem branco que conviveu com os Xavante na aldeia antiga de Sorepré e ali ganhou poder participando das cerimônias. "A História de Marimbondo" revela a coragem e determinação de um menino passando por cerimônias de iniciação e ganhando poder.

Há diferentes crendices envolvendo os marimbondos, como relatado no Norte de Minas Gerais, onde há pessoas que acreditam que pendurar um ninho de marimbondo-bocade-garrafa (provavelmente Chartergus communis Richards, 1978) protege contra "macumba' (PADUA et al., 2017), e há também aqueles que acham que o ninho dentro de casa traz sorte (JOHN, 2011). Já no município de Ouro Fino, sul do estado de Minas Gerais, Moura et al. (2017) documentaram dois relatos: no primeiro, uma entrevistada informou que "Marimbondos no milharal dá espigas bonitas"; o segundo, outra entrevistada disse o seguinte: "Tem uma simpatia com o marimbondo pretinho, se você deixar ele te picar bem de manhãzinha é sinal que você vai ficar mais bonita e ele ajuda a melhorar o sangue. Agora se você desmanchar a casinha dele vai te dar dor de dente." Sra. R. 39 anos (MOURA et al., 2017, p.3).

Na internet há canais do Youtube que também exploram o imaginário popular e trazem diferentes histórias associadas ao humor, como "Geraldinho" (NOGUEIRA, s/d) no "Causo do marimbondo", que na verdade se refere a uma espécie da família Pompilidae, de hábito 
sblitário, que muitas vezes é denominado de marimbondo no Brasil (SILVA et al., 2020); ou associadas a informações biológicas, como o canal "Mosquitos do apocalipse", que traz vídeos sobre "Exu do pasto, pomba de cavalo e outros Marimbondos do Brasil", parte 1 (SOUZA, s/d a) e parte 2 (SOUZA, s/d b).

Sobre rituais, Bollettin (2013) menciona a prática das tribos Xikrin, etnia que habita no estado no Pará, de retirar ninhos de marimbondos manualmente, de modo a confirmar a aptidão dos jovens adultos para o matrimônio. Para o autor, ocorre um fenômeno cultural entre os marimbondos e os Xikrin que fundamenta as bases de sua identidade, a partir da interação dos participantes e de todos os componentes: o indivíduo, o marimbondo e a comunidade.

Essa prática também foi registrada na tribo Kayapó, situada próximo ao Rio Fresco, em que os jovens guerreiros atacam com a mão cerca de cinco ninhos de marimbondos, por acreditarem que esses animais são fortes e grandes defensores de seus ninhos. Os jovens Kayapó devem mostrar-se fortes, combatendo-os em cerimônias. Além disso, indígenas Kayapó acreditam que a organização dos marimbondos é semelhante às suas, como quando comparam os ninhos redondos ao modelo de mundo da tribo (POSEY, 1979).

Já para o povo indígena Ikpeng, vespas têm relevância ritualística, pajés queimam as larvas das denominadas vespas bravas (espécies não identificadas) e passam as cinzas no corpo de adolescentes da tribo como preparo para a guerra. Pela mudança de território, das margens do rio Jatobá para o Parque Indígena do Xingu, o povo Ikpeng não pratica mais esse ritual, por não encontrarem a vespa brava na região (SCHIMIDT e IKPENG, 2006).

Segundo Silva et al. (2020), em sua pesquisa sobre saberes populares acerca de vespas sociais e abelhas no Noroeste do Paraná, os moradores de Porto Camargo responderam que existem algumas simpatias para se recuperar da ferroada de marimbondos: em uma delas a pessoa que levou a ferroada deve cuspir no chão e passar a sola do calçado em cima; outros disseram que colocar um objeto de metal sobre a picada ajuda a reduzir a dor.

Em relação a brincadeiras, ainda grande atenção é dada às "caixas de marimbondo" pelas crianças, que, no interior do estado de Minas Gerais (e provavelmente em outros lugares), atiram canudos de papel com zarabatanas nos ninhos para provocar os ataques, quando todos fogem correndo (SOUZA e ZANUNCIO, 2012).

\subsection{Alimentação}

A FAO (Organização das Nações Unidas para Alimentação e Agricultura), que publicou estudo acerca da entomofagia no mundo (DURST, 2010), afirma que foram reportados 39 grupos étnicos na Amazônia com essa prática, com uma lista em que já estão identificadas 209 espécies de insetos utilizados, havendo predominância também de vespas, entre outros grupos. Rodrigues (2005) apresenta uma pesquisa amplificada demonstrando que desde 1542 há registros de índios Guaranis com práticas de entomofagia.

De acordo com Costa-Neto e Ramos-Elorduy (2006) no que concerne ao uso de vespas sociais na alimentação Brasileira, há o registro de seis espécies, Apoica pallens 
(Fabricius, 1804), Brachygastra lecheguana (Latreille, 1824), Epipona quadrituberculata (Griboldo, 1892), Polybia dimidiata (Olivier, 1791), Polybia occidentalis (Olivier, 1791) e Pseudopolybia vespiceps (Saussure, 1864), sendo os estágios de larva e pupa consumidos regularmente por comunidades indígenas, sobretudo na região amazônica. Entretanto, Bueno et al. (2020), apontam outras 34 spp. alocadas em sete gêneros documentadas no Brasil com potencial de consumo, já que também são consumidas em outros países (JONGEMA, 2017). Ainda sobre hábitos de indígenas Umutina, no Estado do Mato Grosso, Apodonepa e Barreto (2015) relatam registros do uso de marimbondos na dieta de ancestrais diretos, embora tal prática não mais faça parte dos hábitos alimentares dos remanescentes.

Predominantemente, porém, no Brasil, vespas sociais não aparecem com frequência nos repertórios gastronômicos regionais. Silva et al. (2020), por exemplo, versando sobre saberes populares acerca de marimbondos e abelhas no estado do Paraná, observaram que $96 \%$ das pessoas consultadas em seu estudo, não reconhecem esses animais como possibilidades na alimentação ou mesmo na medicina, sendo que os $4 \%$ remanescentes os utilizam como iscas ou para aromatizar aguardentes. Ainda ao norte do Estado de Minas Gerais, Costa-Neto (2000) relata o uso de larvas e pupas de abelhas e vespas para pesca de traíra, Hoplias malabaricus (Bloch, 1794) e cumbá, Parauchenipterus galeatus (Linnaeus, 1766). Povos indígenas Deni, que se situam no estado do Amazonas, também utilizam larvas de vespas para pescar. Uma das formas de coletar é por meio de ninhos que estejam em cima do rio, derrubam-no com uma vareta longa e depois vão buscá-lo correnteza abaixo, para evitar ferroadas de vespas adultas (PEZZUTI e CHAVES, 2009), mas nada é mencionado a respeito da alimentação humana.

Rodrigues (2005) demonstra que entre os Guarani $M$ 'byá, em pesquisa realizada em aldeia no distrito de Parelheiros, periferia de São Paulo, o conhecimento sobre os insetos é transmitido pela oralidade e também por meio das ações, quando os jovens acompanham os mais velhos em alguma prática. Das cinco etnoespécies de vespas citadas, apenas uma foi relatada para uso alimentar. O entrevistado informou que o mel da vespa (em seu idioma kavu) 'Eixu guaçu', também chamada na região de 'lecheguano', por vezes é coletado, mas como é pastoso, é preciso comê-lo junto com o 'favo', por não ser possível realizar a separação de ambos.

Na literatura há referências de que o mel de Lecheguana (Hymenoptera: Vespidae) pode provocar intoxicações, com sintomas de "delírios e bebedeira" (NOGUEIRA-NETO, 1997), muito bem relatado por Saint-Hilaire (2011), o qual vivenciou esse envenenamento no oeste do Rio Grande do Sul, em cujo texto descreve ter sentido dor de estômago, fraqueza, "falha de memória", "nuvem espessa que obscurecia [seus] olhos", "torpor (...) nos dedos," dentre outros. O botânico relata ter perguntado a guaranis, espanhois e portugueses, e todos informaram que havia duas espécies de Lecheguana: "Lecheguana-de-mel-claro" e "Lecheguana-de-mel-vermelho". "O mel da primeira espécie nunca fazia mal", já o outro sim e pode levar à morte (SAINT-HILAIRE, 2011). Provavelmente trata-se da mesma espécie (B. lecheguana), diferindo-se a cor do mel em razão dos tipos de plantas visitadas para coleta de pólen (VENTURINI et al, 2007), o que também podem determinar a toxicidade do mel, como alerta Nogueira-Neto (1997) e as diferentes cores de samora (pólen) encontradas em um mesmo ninho, de acordo com Rodrigues (2005).

Essas informações talvez expliquem a diferença entre as características físicas de cada mel relatado: o que intoxicou Saint Hilaire era vermelho e muito líquido; já o mel entre os 
M'byá (onde não houve relato de intoxicações), foi descrito como pastoso, ainda que a cor não tenha sido citada na pesquisa de Rodrigues (2005). O pesquisador informa que entre os $M$ 'byá o favo é comido junto com o mel e problematiza que isso, dependendo da planta cujo pólen está ali armazenado, pode provocar intoxicação, também mencionado por Saint-Hilaire (2011) e Nogueira-Neto (1997). Os autores não citam os nomes científicos das vespas, mas ambos os ninhos tinham formato oval e estavam a uma altura próxima ao chão, em galhos de arbustos. O ninho do genero Brachygastra encaixase nessa descricão (RICHARDS, 1978; CARPENTER E MARQUES, 2001).

Ainda que esteja restrito geralmente a poucos grupos sociais pertencentes a regiões específicas do país, o uso de marimbondos na alimentação humana constitui prática há muito existente e de implicações não somente nutricionais, mas também medicinais, incluindo esses insetos no grupo da hipotética entomofauna nutracêutica, ao serem relatados usos de vespas sociais, tais como o consumo de mel de algumas espécies do gênero Brachygastra, e ainda o uso alimentar de larvas de marimbondos pelos Tapirapé, Enawê-nawê, Desana e outros índios do rio Uaupés no Amazonas, mencionados por Costa-Neto e Ramos-Elorduy (2006) a partir do levantamento bibliográfico realizado e citado por esses autores. Os nutracêuticos são alimentos que promovem benefícios à saúde para prevenção e/ou tratamento de doenças (MORAES e COLLA, 2006).

\subsection{Medicina popular}

Marimbondos são também utilizados na medicina popular para tratamento de inúmeras doenças. De acordo com Costa-Neto e Pacheco (2005), no povoado de Pedra Branca, em Santa Terezinha, Bahia, são utilizadas diversas espécies de marimbondos para males distintos: parte do ninho do Marimbondo-chapéu (Apoica pallens) para jovens que ainda não tiveram sua menarca; parte do ninho do marimbondo-escopo ou do marimbondosussubera (Eumenini) para caxumba (COSTA-NETO e PACHECO, 2004). Apoica pallens é amplamente citada em outras literaturas para combater ainda outros males, como a asma, novamente atraso de menarca, caxumba, hemorragia pós-parto, hemorragia nasal, pancadas, problemas nos olhos, tontura e até trombose (COSTA-NETO, 1999; 2000; 2005; COSTA-NETO e PACHECO, 2005; MOURA e MARQUES, 2008; ALVES, 2009; 2010).

A espécie B. lecheguana (Latreille, 1824), popularmente denominada "inxu-verdadeiro" ou "marimbondo-de-pote", é utilizada para tosse e asma (MOURA e Marques, 2008). Já Polistes canadensis (Linnaeus, 1758), cujo nome popular é "marimbondo-santa-maria", é usado para tratamento de coqueluche ou tosse (COSTA-NETO, 2001; ALVES, 2009; 2010) e para tontura, asma e derrame (COSTA-NETO, 2013).

Além dessas, também são citadas outras espécies como Polybia sericea (Olivier, 1791), popularmente conhecida por "tarantantã", etnonome citado pelos índios Pankararé (COSTA-NETO, 1998), para o tratamento de trombose (COSTA-NETO, 2000; ALVES, 2009; 2010). Essa mesma espécie é utilizada pelos indígenas Pankararépara tratar aqueles que já tiveram Acidente Vascular Cerebral (AVC), cujo tratamento é realizado pela inalação da fumaça de um ninho queimado (COSTA-NETO, 2002).

A espécie Protopolybia exigua (Saussure, 1854), de nome popular "inxu-cachorro", é utilizada para mal olhado, problemas nos olhos e tabagismo (COSTA-NETO, 2000; ALVES, 2009; 2010) e Synoeca surinama (Linnaeus, 1767), chamado de "marimbondo-tatu", para 
asma e falta de ar (MOURA e MARQUES, 2008; ALVES, 2010). Hermógenes (2016) menciona uso da peçonha de marimbondo (espécie não identificada) para tratamento de bursite em comunidade rural do sul da Bahia.

No município de Ouro Fino, sul do estado de Minas Gerais, Moura et al. (2017) reportam o relato da Sra. M, de 64 anos, demonstrando que a prática medicinal popular dos marimbondos é difundida em diferentes regiões do país, inclusive no sudeste:

\begin{abstract}
Você pega um pedaço do ninho do marimbondo, estes que faz na beira da casa, aquele pretinho, coloca pra ferver com arruda, alecrim e erva cidreira, faz uma cruz com palha e coloca na beira da panela enquanto ferve. Este chá serve pra tudo, dor de cabeça, diarreia, agora pra levantar mulher de resguardo é só colocar uma dose de pinga, serve como fortificante. (MOURA et al., 2017, p.3).
\end{abstract}

Em estudo realizado na comunidade indígena Umutina, no Mato Grosso (APODONEPA e BARRETO, 2015), verificaram que há poucos relatos da utilização de insetos como remédios, mas foi citado uso da "casinha de barro do marimbondo vermelho" para caxumba, e quando colocada sobre o umbigo do recém-nascido favorece a cicatrização. Ao serem questionados por que há poucos usos de insetos para tratamento de enfermidades, alegaram que o conhecimento pode ter se perdido, por não ser transmitido de uma geração à outra e que há falta de informações para essa utilização.

\title{
3.5 Literatura e música popular
}

Na literatura infantil, o corajoso personagem "Pedrinho" do universo do Sítio do Pica-Pau Amarelo, de Monteiro Lobato, costuma afirmar não temer animal algum que não os marimbondos, graças às ferroadas (LOBATO, 2005; SOUZA e ZANUNCIO, 2012), afinal, como já diziam os cantores e compositores Manoel Nunes Pereira (mais conhecido como Peão Carreiro) e Teodoro: "(...) quem mexe com marimbondo tá querendo ferroada...", em sua música denominada "Espinho de juá", interpretada por Zé Tapera e Teodoro, lançada no álbum "Sertão do meu Brasil", pela RCA Records, em 1976 (PRA SEMPRE SERTANEJO, 2016).

Fiuza (2001) observa que, frente às dificuldades de comunicação explícita de ideias consideradas subversivas, durante o período de ditadura militar no Brasil, os compositores utilizavam de linguagem figurativa para criar canções trazendo contundentes críticas políticas, porém de forma velada, a exemplo do trecho transcrito abaixo da música "Casa de Marimbondo", de João Bosco e Aldir Blanc lançada pela RCA Records em 1977 no álbum "Disco de Ouro", cujo registro ISWC é localizado na plataforma da União Brasileira de Compositores (UBC) sob o código T0426296129:

\footnotetext{
Meu samba é casa de marimbondo:

Tem sempre enxame pra quem mexer

Não sabe com quem está falando

Nem quer saber (...)

(João Bosco e Aldir Blanc)
}

A partir do citado contexto, por meio da figura de linguagem da metáfora, pode-se considerar que os compositores associam na música a "Casa de Marimbondo", o Brasil ao samba, e a população brasileira aos marimbondos. Assim, espera-se que com o aumento 
dos riscos e das injúrias infligidas à comunidade, a ação e decisão coletiva do "enxame" seja a reação defensiva que afastará o opressor, ou inimigo natural.

Há ainda o registro da relação entre marimbondos e plantas comuns no cotidiano do povo, por meio dos versos de Ataulfo Alves: "laranja madura / na beira da estrada / tá bichada, Zé / ou tem marimbondo no pé" (TERRA DA GENTE, 2009; CABRAL, 2009).

Na música "Marimbondo" de Sá e Guarabyra (composta por Xico Chaves e Marlui Nobrega Miranda, localizada sob o registro ISWC T0390542069 na plataforma da UBC e lanc,ada pela Som Livre em 1977 no álbum "Pirão de peixe com pimenta"), o Eu-lírico estabelece um paralelo entre seu modo de vida "solto e louco" em oposição ao comportamento sistemático de escolha do substrato para nidificação das vespas sociais, o que é demonstrado pelo verso: "(...) vem fazer no teto o que é correto (...)". Ainda outra vez essa relação é estabelecida no jogo de palavras do trecho "(...) ou vai curtir a bananeira / que tem eira (...) eu não tenho eira nem beira (...)".

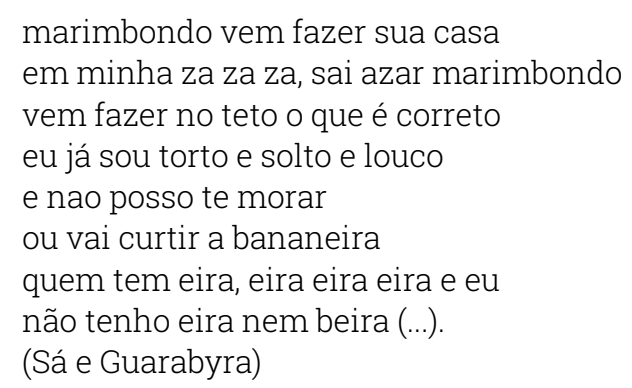

Já Manoel Fernandes de Sousa, em "Marimbondo e Cascavel" (Canção que concorreu ao $2^{\circ}$ Festival de Viola dos Gerais, em 2014), faz menção a diversas facetas comportamentais das vespas sociais e serpentes do gênero Crotalus, animais popularmente conhecidos por sua hostilidade. Referindo-se aos marimbondos, o Eu-lírico menciona o comportamento agressivo, aponta aspectos comportamentais e ecológicos, demonstra o temor cultivado na cultura popular e enfatiza a importância da "ferroada" para o marimbondo quando compara o ferrão ao revólver do soldado:

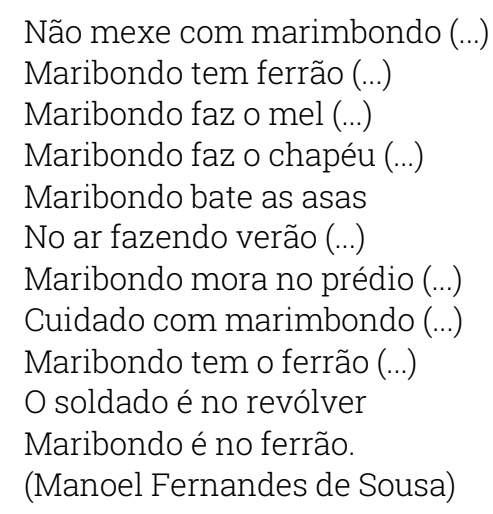

Ainda Luiz Gonzaga, em parceria com José Marcolino, na canção também intitulada "Marimbondo" (lançada em 1964 pela gravadora RCA Records no álbum "A triste partida" e localizada na plataforma UBC pelo registro ISWC T0390321671), em que enaltece ritos relacionados aos costumes da festividade de São João, associa a presença dos marimbondos ao fim da estiagem, período geralmente severo e de longa duração no semiárido. Constatação acurada, considerando o ótimo de atividade das vespas sociais durante a estação chuvosa. 


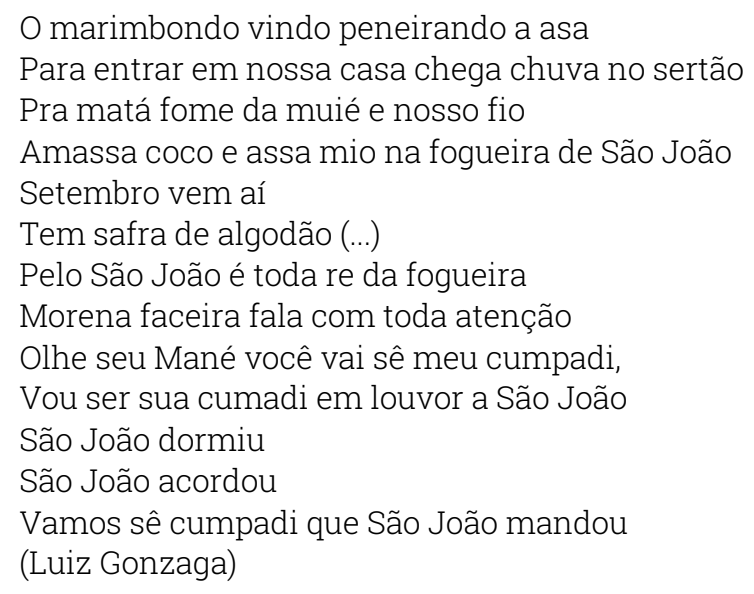

Em Remanso (COSTA-NETO, 2000), a comunidade apresentada demonstra reconhecer que abelhas e marimbondos possuem uma "abeia-mestre" através do verso "Veado comeu na baixa / E descansou no campestre / Abeia-miúda faz mel / Por causa da abeiamestre", cuja importância é explicitada pela ciência, tanto para abelhas quanto para vespas sociais.

\section{Conclusões}

A presença dos marimbondos em múltiplas formas de manifestação cultural demonstra estreita relação entre esses e as comunidades produtoras dos conhecimentos populares relatados.

Além do mais, a suposta hostilidade representada nos relatos do imaginário popular a respeito dos marimbondos mostra-se mais devida à importância da existência dos mitos na construção da identidade dos grupos sociais do que a fenômenos do comportamento animal.

Os dados aqui reportados representam mais um passo na direção de se repensarem as práticas adotadas no Brasil em relação aos recursos naturais, uma vez que os sistemas ecológicos apresentam redes intrincadas de relações em que cada unidade desempenha um papel singular e fundamental.

Os registros aqui discutidos não representam a totalidade quanto à presença desses animais na cultura popular brasileira, já que estando tão intimamente entranhada aí, tornar-se-ia impossível a compilação de tudo o que já se escreveu, contou e cantou sobre a relação entre o brasileiro do interior e os marimbondos. O trabalho mostra, porém, em linhas gerais, a natureza da relação entre esses sujeitos e demonstra seguramente que as vespas sociais são importantes para a vida do homem do campo e fazem parte do folclore e da identidade do povo brasileiro.

\section{Referências -}

ALVARENGA, R. B.; CASTRO, M. M; SANTOS-PREZOTO, H. H.; PREZOTO, F. Nesting of social wasps (Hymenoptera, Vespidae) in urban gardens in Southeastern Brazil.

Sociobiology, v.55, n.2, p.445-452, 2010. Diponível em: 
$<$ https://www.researchgate.net/publication/266853554_Nesting_of_Social_Wasps_Hym enoptera_Vespidae_in_Urban_Gardens_in_Southeastern_Brazil $>$ Acesso em:

05/06/2021.

ALVES, R. R. N. Fauna used in popular medicine in Northeast Brazil. Journal of Ethnobiology and Ethnomedicine, v.5, n.1, p.1-11, 2009. DOI: 10.1186/1746-4269-5-1. Disponível em: <https://ethnobiomed.biomedcentral.com/articles/10.1186/1746-4269-51> Acesso em: 05/06/2021.

ALVES, R. R. N.; DIAS, T. L. P. Usos de invertebrados na medicina popular no Brasil e suas implicações para conservação. Mongabay.com Open Access Journal - Tropical Conservation Science Vol.3 (2):159-174, 2010. Disponível em: <https://journals.sagepub.com/doi/pdf/10.1177/194008291000300204> Acesso em: 05/06/2021.

APODONEPA, L. A.; BARRETO, M. R. Conhecimento Etnoentomológico na Comunidade Indígena Umutina (Mato Grosso, Brasil). Etnobiologia, v. 13, n. 3, p.68-79, 2015. Disponível em: <https://dialnet.unirioja.es/descarga/articulo/5294500.pdf> Acesso em: 05/06/2021.

ARAUJO, R. M. Os Tupinismos na formação do léxico portugués do Brasil. Revista Philologus, Ano 14, N 40 - Supl. Rio de Janeiro: CiFEFiL, jan./abr.2008. Disponível em: <http://www.filologia.org.br/rph/ANO14/40SUP/008.pdf> Acesso em: 08/08/2021.

AUAD, A. M.; CARVALHO, C. A.; CLEMENTE, M. A.; PREZOTO, F. Diversity of social wasps (Hymenoptera) in a silvipastoral system. Sociobiology, v.55, n.2, p.627-636, 2010.

Disponível em:

https://www.researchgate.net/publication/267748800_Diversity_of_Social_Wasps_Hy

menoptera_in_a_Silvipastoral_System> Acesso em: 05/06/2021.

BRITO, E. L. S.; ARAGÃO, M.; SANTOS, G. M. M. Colony defensive behavior by the swarmfounding wasp Parachartergus pseudoapicalis. increase on investment predicts the intensity of nest defense. Insectes Sociaux, v.65, n.3, p.411-417, 2018. Disponível em: <https://link.springer.com/article/10.1007/s00040-018-0627-6> Acesso em: 05/06/2021.

BOLLETTIN, P. Amiy: os Xikrin, os Marimbondos e os Outros. Revista de Antropologia da UFSCar, v.5, n.1, p.30-47, 2013. Disponível em: <http://www.rau.ufscar.br/wpcontent/uploads/2015/05/vol5no1_02.Paride.pdf> Acesso em: 23/05/2021.

BOMFIM, B. L. S.; FILHO, I. C. F.; Farias, J. C.; FRANÇA, S. M.; BARROS, R. F. M.; SILVA, P. R. R. Etnoentomologia em comunidade rural do cerrado piauiense. Desenvolvimento e Meio Ambiente, Curitiba, v. 39, p. 189-205, 2016. Disponível em: <https://revistas.ufpr.br/made/article/view/44597> Acesso em: 07/06/2021.

BUENO, E. T.; CARVALHO, B. A. P.; SOUZA, M. M. Marimbondos (Hymenoptera, Vespidae) como fonte de alimentação humana no Brasil: uma revisão de literatura. Ethnoscientia, v.5, n.1, 2020. Disponível em:

<https://periodicos.ufpa.br/index.php/ethnoscientia/article/view/10302>. Acesso em: 07/06/2021. 
CABRAL, S. Ataulfo Alves: Vida e Obra. São Paulo: Companhia Editora Nacional: Lazuli. 176p, 2009.

CARPENTER, J. M.; MARQUES, O. M. Contribuição ao Estudo dos Vespídeos do Brasil. Universidade Federal da Bahia, Departamento de Fitotecnia. Série Publicações Digitais, v. 3, CD-ROM. 147p, 2001. Disponível em:

$<$ https://www.academia.edu/19731202/Carpenter_and_Marques_2001_Contribui\%C3\%A7 \%C3\%A3o_ao_Estudo_dos_Vesp\%C3\%ADdeos_do_Brasil_Insecta_Hymenoptera_Vespoi dea_Vespidae_> Acesso em: 05/06/2021.

CHAVARRIA-PIZARRO, L.; WEST-EBERHARD, M. J. The behavior and natural history of Chartergellus a little-known genus of neotropical social wasps (Vespidae: Polistinae: Epiponini). Ethology Ecology \& Evolution, v.2, n.4, p.317-343, 2010. DOI: https://doi.org/10.1080/03949370.2010.510035.

COSTA-NETO, E. M. Folk taxonomy and cultural significance of "abeia" (Insecta, Hymenoptera) to the Pankararé, northeastern Bahia state, Brazil. Journal of Ethnobiology 18(1):1-13, 1998.

COSTA-NETO, E. M. Recursos animais utilizados na medicina tradicional dos índios Pankararés, que habitam no Nordeste do Estado da Bahia, Brasil. Actualidades Biologicas. v, 21, n. 70, p.69-79, 1999. Disponível em: <https://revistas.udea.edu.co/index.php/actbio/article/view/329774> Acesso em: 05/06/2021.

COSTA-NETO, E. M. Conhecimento e Usos Tradicionais de recursos faunísticos por uma comunidade afro-brasileira. Resultados preliminares. Interciência, v. 25, n.9, p.423-431, 2000. Disponível em:

<https://www.centroafrobogota.com/attachments/article/10/33905105faunanumaComunidadeafrobras.pdf> Acesso em: 23/05/2021.

COSTA-NETO, E. M. A cultura pesqueira do litoral Norte da Bahia: etnoictiologia, desenvolvimento e sustentabilidade. Bahia: EDUFBA; Maceió: EDUFAL. 159p., 2001.

COSTA-NETO, E. M. The Use of Insects in Folk Medicine in the State of Bahia, Northeastern Brazil, With Notes on Insects Reported Elsewhere in Brazilian Folk Medicine. Human Ecology, v. 30, n. 2, p.245-263, 2002. DOI: 10.1023/A:1015696830997

COSTA-NETO, E. M. Insetos como fontes de alimento para o homem: valoração de recursos considerados repugnantes. Interciência, v. 28, n. 3, 2003.

COSTA-NETO, E. M. La etnoentomología de las avispas (Hymenoptera, Vespoidea) en el poblado de Pedra Branca, estado da Bahia, nordeste de Brasil. Boletín de la Sociedad Entomológica Aragonesa, no 34 (2004): 247 - 262. Disponível em: <http://seaentomologia.org/PDF/BOLETIN_34/B34-056-247.pdf> Acesso em: 08/08/2021.

COSTA-NETO, E. M. Animal-based medicines: biological prospection and the sustainable use of zootherapeutic resources. Anais da Academia Brasileira de Ciências, v.77, n.1, p.33-43, 2005. Disponível em: 
<https://www.scielo.br/j/aabc/a/HCwFfs6BthD96zLjp7hfVfQ/?lang=en> Acesso em: 05/06/2021.

COSTA-NETO, E. M. Análise etnossemântica de nomes comuns de abelhas e vespas (Insecta, Hymenoptera) na terra indígena Pankararé, Bahia, Brasil. Cadernos de Linguagem e Sociedade, v.14, n.1, p.237-251, 2013. DOI: 10.26512/les.v14i1.22248

COSTA-NETO, E. M.; PACHECO, J. M. A construção do domínio etnozoológico "inseto" pelos moradores do povoado de Pedra Branca, Santa Terezinha, Estado da Bahia. Acta Scientiarum. Biological Sciences, v. 26, n. 1, p.81-90, 2004. Disponível em: <https://periodicos.uem.br/ojs/index.php/ActaSciBiolSci/article/view/1662> Acesso em: 05/06/2021.

COSTA-NETO, E. M.; PACHECO, J. M. Utilização medicinal de insetos no povoado de Pedra Branca, Santa Terezinha, Bahia, Brasil. Biotemas, v.18, n.1, p.113-133, 2005. Disponível em: $<$ https://periodicos.ufsc.br/index.php/biotemas/article/view/21470> Acesso em: 05/06/2021.

COSTA-NETO, E. M.; RAMOS-ELORDUY, J. Los insectos comestibles de Brasil: etnicidad, diversidad e importancia en la alimentación. Boletín de la Sociedad Entomológica Aragonesa, V. 38, p.423-442, 2006. Disponível em: <http://seaentomologia.org/PDF/GeneraInsectorum/GE-0062.pdf> Acesso em: 05/06/2021.

DALlÓ, J. B.; SOUZA, M. M.; COELHO, E. L.; BRUNISMANN, A. G. Vespas sociais (Hymenoptera, Vespidae) em cultura de bucha vegetal Luffa aegyptiaca Mill. Revista Agrogeoambiental, v.9, n.4, 2017. DOI: http://dx.doi.org/10.18406/2316-1817v10n120181043.

DURST, P. B.; JOHNSON, D. V.; LESLIE, R. N.; SHONO, K. Edible Forest Insects: Humans Bite Back. Food and Agriculture Organization of the United Nations. FAO, 2010. Disponível em: <http://www.fao.org/3/i1380e/i1380e.pdf>. Acesso em: 23/05/2021.

FIUZA, A. F. Entre cantos e chibatas: a pobreza em rima rica nas canções de João Bosco e Aldir Blanc. 213f. Dissertação (Mestrado). Universidade Estadual de Campinas UNICAMP, Campinas, SP, 2001. Disponível em: <http://repositorio.unicamp.br/jspui/handle/REPOSIP/253005> Acesso em: 05/06/2021.

GIANNOTTI, E. Arquitetura de ninhos de Mischocyttarus cerberus styx Richards, 1940 (Hymenoptera, Vespidae). Revista Brasileira de Zoociências, v.1, n.1, p.7-18, 1999. Disponível em: <https://periodicos.ufjf.br/index.php/zoociencias/article/view/24295> Acesso em: 05/06/2021.

HERMOGENES, G. C. Uso alimentar e medicinal de insetos em comunidades rurais do sul da Bahia: uma abordagem etnozoológica. 67f. Dissertação (Mestrado). Universidade Estadual de Santa Cruz, Ilhéus, BA, 2016. Disponível em: $<$ http://nbcgib.uesc.br/ppgzoologia/wp-content/uploads/2018/07/Dissertao-deMestrado_Gabriella-Carvalho-Hermgenes.pdf> Acesso em: 05/06/2021.

JACQUES, G. C.; OliveIRA, D. C.; SOUZA, M. M.; SILVEIRA, L. C. P. The use of Polistes versicolor (Olivier, 1971) in the control of Ascia monuste orseis (Godart, 1819) in kale cultivation. Agrogeoambiental, v. 11, n.4, p. 96-106, 2019. Disponível em: 
$<$ https://agrogeoambiental.ifsuldeminas.edu.br/index.php/Agrogeoambiental/article/vi ew/1395> Acesso em: 05/06/2021.

JONGEMA, Y. List of edible insects of the world (April 1, 2017). Laboratory of Entomology, Wageningen University, Wageningen. 2017. Disponível em: https://www.wur.nl/en/Research-Results/Chair-groups/Plant-Sciences/Laboratory-ofEntomology/Edible-insects/Worldwide-species-list.htm.

JOHN, L. Marcos dos Marimbondos. Brasileiros, Camirim Editorial: São Paulo, 51: 82-85, 2011

LOBATO, M. O Saci (1921). São Paulo: Editora Brasiliense, 56a edição, 2005. Disponível em: <https://www.fortaleza.ce.gov.br/images/Cultura/Monteiro_Lobato_-_O_Saci.pdf> Acesso em: 10/06/2021.

MATEUS, S; NOLL, F. B.; ZUCCHI, R. Morphological caste differences in neotropical swarm-founding polistine wasps: Parachartergus smithii (Hymenoptera: Vespidae). Journal of the New York Entomological Society, p.129-139, 1997. Disponível em: <https://www.researchgate.net/publication/289302249_Morphological_caste_differenc es_in_the_neotropical_swarmfounding_polistine_wasps_Parachartergus_smithii_hymenoptera_vespidae> Acesso em: 05/06/2021.

MENDONÇA, R. A Influência africana no português do Brasil. Brasília: FUNAG, 200 p., 2012. Disponível em: <http://funag.gov.br/biblioteca/download/983Influencia_Africana_no_Portugues_do_Brasil_A.pdf> Acesso em: 07/06/2021.

MELO, M. "Guerra dos Maribondos". Revista do Instituto Archeologico, Histórico e Geográfico Pernambucano (RIHAP), n.22, p.38-47, 1920.

MORAES, F. P.; COLLA, L. M. Alimentos funcionais e nutracêuticos: definições, legislação e benefícios à saúde. Revista Eletrônica de Farmácia Vol 3(2), 109-122, 2006. Disponível em: <https://www.revistas.ufg.br/REF/article/view/2082/2024> Acesso em: 28/05/2021.

MOURA, F. B. P.; MARQUES, J. G. W. Zooterapia popular na Chapada Diamantina: uma Medicina incidental? Ciência \& Saúde Coletiva, v.13, n.2, p.2179-2188, 2008. Disponível em: $<$ https://www.scielo.br/j/csc/a/5Qd7stgcBfsGNd64mTPFYvN/?lang=pt> Acesso em: 05/06/2021.

MOURA, I. A.; FRANCISCO, J. P.; SOUZA, M. M. Abordagem etnoentomológica no município de Ouro Fino, Sul do Estado de Minas Gerais. In: 9a Jornada Científica e Tecnológica do IFSULDEMINAS e $6^{\circ}$ Simpósio da Pós-Graduação. 2017. Disponível em: <https://jornada.ifsuldeminas.edu.br/index.php/jcmch4/jcmch4/paper/viewFile/3236/2 730> Acesso em: 05/06/2021.

MOTA, A. F.; PIMENTA, E. F.; RIBEIRO, G. F. Cera e Mel: as abelhas na cultura Xakriabá. Formação Intercultural para Educadores Indígenas. 53f. Monografia (Graduação) Universidade Federal de Minas Gerais/UFMG, Belo Horizonte, MG, 2017. Disponível em: $<$ https://www.biblio.fae.ufmg.br/monografias/2017/TCC-

ALINE_ELIZANDRA_E_GENIVALDO.pdf> Acesso em: 05/06/2021. 
NOGUEIRA, G. Causos, proza e rizadas (sic.). Geraldinho Causo do Marimbondo. Youtube, s/d. Disponível em: <https://youtu.be/uCbxFFYjfR0 Youtube> Acesso em 04/06/2021.

NOGUEIRA-NETO, P. Vida e criação de abelhas indígenas sem ferrão. São Paulo: Ed. Nogueirapis, 445p., 1997. Disponível em:

<http://www.acaic.com.br/site/pdf/livro_pnn.pdf> Acesso em: 25/05/2021.

OLIVEIRA, T. C. T.; SOUZA, M. M.; PIRES, E. P. Nesting habits of social wasps (Hymenoptera: Vespidae) in forest fragments associated with anthropic areas in southeastern Brazil. Sociobiology, v. 64, n.1, p.101, 2017. Disponível em: $<$ http://periodicos.uefs.br/ojs/index.php/sociobiology/article/view/1073> Acesso em: 05/06/2021.

PADUA, D. C.; SOUZA, M. M.; BRUNISMANN, A. G.; COELHO, E. L.; PIRES, E. P. Conhecimento popular sobre vespas sociais (Hymenoptera, Vespidae) nas comunidades do entorno do refúgio da vida silvestre do Rio Pandeiros, norte do estado de Minas Gerais. Ethnoscientia, v. 2, n.1, p.01-10, 2017. Disponível em: $<$ https://periodicos.ufpa.br/index.php/ethnoscientia/article/view/10184/7041> Acesso em: 07/06/2020.

PAPPIANI, A.; LACERDA, M.P. Aiho'Ubuni Wasu'U- o lobo guará e outras histórias do povo Xavante. $1^{a}$ edição. Editora Ikore: São Paulo, 2014.

PEZZUTI, J.; CHAVES, R. P.; Etnografia e manejo de recursos naturais pelos índios Deni, Amazonas, Brasil. Acta Amazonica, vol. 39(1), p.121-138, 2009. Disponível em: <https://www.scielo.br/j/aa/a/PqX8YmHg6SZSKbCYs95ZPmq/?lang=pt> Acesso em: 05/06/2021.

POSEY, D. A. Kayapó controla inseto com uso adequado do ambiente. Revista Atualidade Indígena, v. 3, n. 14, p.47-58, 1979. Disponível em: $<$ https://documentacao.socioambiental.org/documentos/KYP00003.pdf> Acesso em: 05/06/2021.

POVOS INDÍGENAS NO BRASIL (PIB). Línguas. s/d. Disponível em: <https://pib.socioambiental.org/pt/L\%c3\%adnguas> Acesso em: 08/08/2021.

PRA SEMPRE SERTANEJO. Disco é cultura. Discografias Zé Tapera \& Teodoro (1976). Sertão do meu Brasil, 2016. Disponível em: <https://www.prasempresertanejo.com.br/search/label/Ze\%20Tapera\%20e\%20Teodoro> Acesso em: 18/08/2021.

PREZOTO, F.; MACIEL, T. T.; DETONI, M.; MAYORQUIN, A. Z.; BARBOSA, B. C. Pest Control Potential of Social Wasps in Small Farms and Urban Gardens. Insects, v.10, n.7, p.192, 2019. Disponível em: <https://www.ncbi.nlm.nih.gov/pmc/articles/PMC6681282/> Acesso em: 05/06/2021.

RICHARDS, O. W. The social wasps of the Americas, excluding the Vespinae. British Museum (Natural History), 1978. 
RODRIGUES, A. S. Etnoconhecimento sobre abelhas sem ferrão: saberes e práticas dos índios Guarani M’byá na Mata Atlântica. 253f. Dissertação (Mestrado) - Escola Superior de Agricultura Luiz de Queiroz (ESALQ/USP), Piracicaba, SP, 2005. Disponível em: $<$ https://teses.usp.br/teses/disponiveis/91/91131/tde-15072005-150814/pt-br.php> Acesso em: 05/06/2021.

SAINT-HILAIRE, A. Do envenenamento causado pelo mel da vespa lecheguana (1824) In: SAINT-HILAIRE, A. História das Plantas mais Notáveis do Brasil e do Paraguai/ Auguste de Saint-Hilaire; tradução Cleonice Paes Barreto Mourão; [organização Maria das Graças Lins Brandão e Christopher William Fagg]. Editora Fino Traço: Belo Horizonte, MG, 2011. Disponível em: <http://www.ceplamt.org.br/wpcontent/uploads/2014/02/HistoriaPlantas-SaintHilaire-PROVA-5aCorrecao.pdf> Acesso em: 26/05/2021.

SANTOS, E. (Ed.) Os Insetos. Belo Horizonte: Editora Itatiaia. 243p, 1985.

SANTOS, J. R. L.; THOMAS, S. E. O.; DORVAL, A.; PASA, M. C. A etnoentomologia na comunidade Mata Cavalo de Baixo em Nossa Senhora do Livramento, MT, Brasil. Biodiversidade, v.14, n.2. p.84-92, 2015. Disponível em: <https://periodicoscientificos.ufmt.br/ojs/index.php/biodiversidade/article/view/2895> Acesso em: 05/06/2021.

SANTOS, M. C. F.; FERREIRA, B. P. A Influencia do Tupi na linguagem popular referente ao meio ambiente do litoral sul de pernambuco, Brasil. Revista Tropical Oceanography. Univ. Fed. PE, Recife, 28(1): 87- 96, 2000. Disponível em: $<$ https://periodicos.ufpe.br/revistas/TROPICALOCEANOGRAPHY/article/viewFile/2721/2 2 39> Acesso em: 08/08/2021.

SCHIMIDT, M. V. C.; IKPENG, K. Ikpeng - Mobilização para resgatar recursos naturais tradicionais. Povos Indígenas No Brasil- 2001/2005, v.0, p. 671-674, 2006.

SILVA, J. V. N.; SOUZA, M. M.; SOUZA, A. S. B.; ALMEIDA, J. A. M.; MESSAGE, H. J.; GOMES, P. P. Saberes populares acerca de vespas sociais (Vespidae) e abelhas (Apidae) na Mata Atlântica do noroeste do Paraná, sul do Brasil. Ethnoscientia, v. 5, n.1, 2020. Disponível em: <https://periodicos.ufpa.br/index.php/ethnoscientia/article/view/10287 > Acesso em: 25/05/2021.

SILVEIRA, O. T.; SILVA, S. S.; FELIZARDO, S. P. S. Notes on social wasps of the group of Mischocyttarus (Omega) punctatus (Ducke), with description of six new species (Hymenoptera, Vespidae, Polistinae). Revista Brasileira de Entomologia, v.59, n.3, p.154168, 2015. DOI: https://doi.org/10.1016/j.rbe.2015.07.006 .

SOMAVILLA, A.; OLIVEIRA, M. L.; SILVEIRA, O. T. Guia de identificação dos ninhos de vespas sociais (Hymenoptera, Vespidae, Polistinae) na Reserva Ducke, Manaus, Amazonas, Brasil. Revista Brasileira de Entomologia, v. 56, n. 4, p. 405-414, 2012. DOI: https://doi.org/10.1590/S0085-56262012000400003.

SOUZA, M. M. Os mosquitos do Apocalipse. Exu do pasto, pomba de cavalo e outros marimbondos do Brasil Parte I. Youtube, s/d a. Disponível em: <https://youtu.be/fqG5DEICSxo> Acesso em: 04/06/2021. 
SOUZA, M. M. Os mosquitos do Apocalipse. Exu do pasto, pomba de cavalo e outros marimbondos do Brasil Parte II. Youtube s/d b. Disponível em: <https://youtu.be/fAq0YaH4Foc> Acesso em: 04/06/2021.

SOUZA, M. M.; SILVA, M. A.; SILVA, M. J.; ASSIS, N. G. R. Barroso, a capital dos marimbondos: vespas sociais (Hymenoptera: Vespidae) do município de Barroso, Minas Gerais. MG BIOTA, v.1, n.3, p.24-38, 2008. Disponível em:

<http://repositorio.ufla.br/bitstream/1/2923/1/TESE_Vespas\%20sociais\%20\%28Hymenop tera\%20Vespidae\%29\%20indicadoras\%20do\%20grau\%20de\%20conserva\%C3\%A7\%C3\%A3 o\%20de\%20florestas\%20rip\%C3\%A1rias.pdf> Acesso em: 05/06/2021.

SOUZA, M. M.; ZANUNCIO, J. C. (Eds.). Marimbondos-Vespas Sociais (Hymenoptera: Vespidae). $1^{a}$ ed. Viçosa: Editora UFV. 79p, 2012.

SOUZA, M. M; TEOFILO-GUEDES, G.; MILANI, L. R.; SOUZA, A. S. B.; GOMES, P. P. Social Wasps (Vespidae: Polistinae) from the Brazilian Atlantic Forest. Sociobiology, v. 67, n.1, p.01-12, 2020a. Disponível em:

<http://periodicos.uefs.br/index.php/sociobiology/article/view/4597/0> Acesso em: 05/06/2021.

SOUZA, M. M.; TEOFILO-GUEDES, G.; BUENO, E. T.; MILANI, L. R.; SOUZA, A. S. B. Social Wasps (Hymenoptera, Polistinae) from the Brazilian Savanna. Sociobiology, v. 67, n.2, p.129-138, 2020b. Disponível em:

<http://periodicos.uefs.br/ojs/index.php/sociobiology/article/view/4958> Acesso em: 05/06/2021.

SOUZA, M. M.; CLEMENTE, M. A.; TEOFILO-GUEDES, G. Nest camouflage records on five social wasp species (Vespidae, Polistinae) from southeastern Brazil. EntomoBrasilis, v.13, 2020c. DOI:https://doi.org/10.12741/ebrasilis.v13.e929.

STARR, C. K. The nest as the locus of social life. In: ROSS, K.G.; MATTHEWS, R.W. (Orgs.) The Social Biology of Wasps. Ithaca: Cornell University Press, pp. 520-539, 1991.

STRASSMANN, J. E.; HUGHES, C. R.; QUELLER, D. C. Colony defense in the social wasps, Parachartergus colobopterus. Biotropica, v.22, n.3, p.324-327, 1990. DOI: https://doi.org/10.2307/2388546.

TERRA DA GENTE. No ninho dos marimbondos. São Paulo, n. 63, p.36-41, 2009.

VENTURINI, K. S.; SARCINELLI, M. F.; SILVA, L. C. Características do Mel. Boletim Técnico - PIE-UFES: 01107. Espírito Santo: Universidade Federal do Espírito Santo (UFES), 2007. Disponível em: $<$ https://www.agais.com/telomc/b01107_caracteristicas_mel.pdf> Acesso em: $10 / 08 / 2021$.

WENZEL, J. W. A. Generic key to the nests of Hornets, Yellow-jackets, and paper wasps worldwide (Vespidae: Vespinae, Polistinae). American Museum Novitates, n.3224, p.1-39, 1998. 
Recebido em: 14/06/2021 Aprovado em: 23/09/2021

Publicado em: 16/11/21 